\title{
Electrochemical removal of haloacetic acids in a three-dimensional electrochemical reactor with Pd-GAC particles as fixed filler and Pd-modified carbon paper as cathode
}

\author{
Xu Zhao ${ }^{a}$, Angzhen $\mathrm{Li}^{a, b}$, Ran Mao ${ }^{a}$, Huijuan Liu ${ }^{a}$, Jiuhui $Q u^{a, *}$ \\ a State key Laboratory of Environmental Aquatic Chemistry, Research Center for Eco-Environmental Sciences, \\ Chinese Academy of Sciences, Beijing 100085, China \\ ${ }^{\mathrm{b}}$ China Academy of Urban Planning and Design, Beijing 100044, China
}

\section{A R T I C L E I N F O}

\section{Article history:}

Received 15 July 2013

Received in revised form

16 December 2013

Accepted 21 December 2013

Available online 2 January 2014

\section{Keywords:}

Pd-C electrode

Pd-GAC

Three-dimensional electrochemical reactor

Electrocatalytic reduction

Haloacetic acids

\begin{abstract}
A B S T R A C T
The reductive removal of haloacetic acids (HAAs) in a three-dimensional electrochemical continuous reactor with Pd-granular activated carbon (Pd-GAC) particles as fixed filler and Pd-modified carbon paper ( $\mathrm{Pd}-\mathrm{C}$ ) as cathode was studied in this research. $\mathrm{Pd}-\mathrm{C}$ electrode was prepared from $\mathrm{PdCl}_{2}$ via electrodeposition onto carbon paper. Pd-GAC particles were prepared by the impregnation of $\mathrm{Pd}^{2+}$ ions onto GAC. Efficient electrocatalytic reduction of HAAs in this reactor was exhibited. Effects of current density, initial HHAs concentration, and hydraulic retention time on the HHAs removal were investigated. Under the current density of $0.3 \mathrm{~mA} / \mathrm{cm}^{2}$, HAAs with initial concentration of $120 \mu \mathrm{g} / \mathrm{L}$ were reduced to be less than $60 \mu \mathrm{g} / \mathrm{L}$ with hydraulic retention time of $20 \mathrm{~min}$. Electron transfer and HAAs diffusion both played an important role in controlling the electro-reduction process under the conditions of current density less than $0.6 \mathrm{~mA} / \mathrm{cm}^{2}$ with an initial HAAs concentration ranging from 120 to $600 \mu \mathrm{g} / \mathrm{L}$. However, the HAAs diffusion became the primary ratelimiting step when the current density was higher than $0.6 \mathrm{~mA} / \mathrm{cm}^{2}$. The $\mathrm{Pd}^{0}$ and $\mathrm{Pd}^{2+}$ species were detected by X-ray photoelectron spectroscopy. The stability of the electrochemical reactor in the reduction removal of HAAs was also exhibited.
\end{abstract}

(c) 2013 Elsevier Ltd. All rights reserved.

\section{Introduction}

Haloacetic acids (HAAs) are important disinfection byproducts in chlorinated water (Christman et al., 1983; Hong et al., 2013). Because of their toxicity and carcinogenicity, the concentrations of HAAs are regulated by the U.S. Environmental Protection Agency (Xu and Weisel, 2003; Gan et al., 2013). The
Disinfectants/Disinfection Byproducts Rule established a maximum contaminant level (MCL) of $60 \mu \mathrm{g} / \mathrm{L}$ for the sum of five HAAs (HAA5 = MCAA + MBAA + DCAA + DBAA + TCAA) under the Stage I (Pontinus, 1999). Biodegradation and reverse osmosis are used to remove HAAs from chlorinated water (Linge et al., 2013; McRae et al., 2004). The reverse osmosis treatment may generate a polluted waste that should be treated (Linge et al., 2013). Biodegradation may cause bacterial

\footnotetext{
* Corresponding author. Tel.: +8610 62849151; fax: +86 1062923558

E-mail address: jhqu@rcees.ac.cn (J. Qu).
} 
contamination in the treated water (McRae et al., 2004). Another possibility is the application of $\mathrm{TiO}_{2}$ photocatalysis, but there exists the problem of $\mathrm{TiO}_{2}$ separation from aqueous phase (Czili and Horvath, 2009; Spangeberg et al., 1996). The catalytic dehalogenation of HAAs is a suitable decontamination method whereas it usually requires an addition of reducing agent (such as hydrogen and zero-valent iron) (Zhou et al., 2013; Hozalski et al., 2001; Tang et al., 2013).

Electrochemical reduction is found to be the efficient and friendly method for the removal of HAAs. Because it ensures the selective removal of halogen atoms from HAAs without producing toxic byproducts or adding any toxic chemicals (Korshin and Jensen, 2001; Li et al., 2007; Altamar et al., 2010). The use of efficient catalysts can decrease the energy consumption and promotes the reaction rates during the electrochemical process. Specifically, palladium (Pd) catalysts were found to show good catalytic activity for degradation of halogenated organic compounds (HOCs) and they can operate efficiently within a broad range of pollutants concentration (Lingaiah et al., 1999; Mackenzie et al., 2006; Rego et al., 2010; Martinez et al., 2013). In our previous study, it was demonstrated that the Pd-C electrode prepared via electrodeposition showed higher activity in the dechlorination of chloroacetic acids than via impregnation and calcinations (Li et al., 2012). Some researchers have reported that dechlorination of HOCs at cathode surfaces may occur through both direct and indirect mechanisms ( $\mathrm{Li}$ et al., 2012; Li and Farrell, 2000; Wang et al., 2010; De Pedro et al., 2011). It was observed that the presence of $\mathrm{Pd}(0)$ nanoparticles played a significant role in forming atomic $\mathrm{H}^{*}$ to realize indirect reduction process which could achieve the complete dechlorination of chloroacetic acids ( $\mathrm{Li}$ and Farrell, 2000).

However, these studies are mainly carried out in batch reactors and with distilled water containing electrolyte and HAAs. The effect of coexisted ions on the performance of the electrochemical reactor was little investigated (Li et al., 2007; Altamar et al., 2010; Li et al., 2012). Besides, it has been recognized that the removal efficiency of the pollutants could be increased by use of three-dimensional electrode with extensive specific surface area in comparison to conventional two-dimensional electrodes (Kong et al., 2006; Mascia et al., 2012). Thus, optimization of the reactor configuration is useful for a high removal efficiency of the pollutants in the electrochemical process. The removal efficiency was defined as the percentage of haloacetic acid initially present that has been removed.

In this study, Pd-granular activated carbon (Pd-GAC) was prepared and used as fixed filler for the cathode cell; a threedimensional electrochemical reactor was established for effective electrochemical dehalogenation of HAAs. Pdmodified carbon paper (Pd-C) cathode was used as cathode, which was prepared from $\mathrm{PdCl}_{2}$ via electrodeposition onto carbon paper (Li et al., 2012). GAC was used as support of catalysts because of its low cost, high surface area and high hydrodehalogenation activity (Wei et al., 2010). The electrochemical removal of HHAs in a simulated drinking water using the three-dimensional electrochemical reactor was investigated. The stability of the electrochemical reactor in the reduction removal of HAAs was also exhibited.

\section{Materials and methods}

\subsection{Preparation of the Pd-C electrode and Pd-GAC}

The Pd-C electrode was prepared via our previously reported electrodeposition method (Li et al., 2012). The electrodeposition of $\mathrm{Pd}(0)$ was carried out by dipping the cleaned carbon paper in dichlorodiamminepalladium $\left[\mathrm{Pd}\left(\mathrm{NH}_{3}\right)_{2} \mathrm{Cl}_{2}\right]$ complex (plating solution), composed of $1 \mathrm{mM}$ palladium chloride $\left(\mathrm{PdCl}_{2}\right)$ and $10 \mathrm{mM}$ ammonium chloride solution (Wang and $\mathrm{Qu}, 2006)$. The deposition current and time was selected as $1 \mathrm{~mA} / \mathrm{cm}^{2}$ and $30 \mathrm{~min}$, respectively. The $\mathrm{Pd}-\mathrm{C}$ electrode was treated at $200^{\circ} \mathrm{C}$ for $120 \mathrm{~min}$ under flowing hydrogen (flow rate: $100 \mathrm{~mL} / \mathrm{min}$ ). The Pd-GAC was prepared using the impregnation and calcination method. GAC was firstly immersed in a $2.5 \%(\mathrm{w} / \mathrm{w})$ nitric acid solution with the magnetic stirrer, and then was washed and calcined at $200{ }^{\circ} \mathrm{C}$ for $120 \mathrm{~min}$ in order to enhance the binding force between GAC and metal ions. The pretreated GAC was then immersed in $\mathrm{PdCl}_{2}$ solution which contained $0.1 \mathrm{M}$ hydrochloric acid, and was ultrasonically treated for $360 \mathrm{~min}$. Then, the obtained samples were dried at $120^{\circ} \mathrm{C}$ and calcined at $300^{\circ} \mathrm{C}$ for $120 \mathrm{~min}$, and was finally reduced in hydrogen at $200^{\circ} \mathrm{C}$ for $300 \mathrm{~min}$ (flow rate: $100 \mathrm{~mL} / \mathrm{min}$ ). The Pd content is determined to be $3 \mathrm{wt} \%$ with respect to GAC in this study.

\subsection{Three-dimensional electrochemical reactor and the experimental procedure}

The three-dimensional electrochemical reactor was shown in Fig. 1. All electrochemical experiments were carried out in this reactor with two-compartment cells. The anode cell and cathode cell (effective volume $=300 \mathrm{~mL}$ ) were separated by a cation-

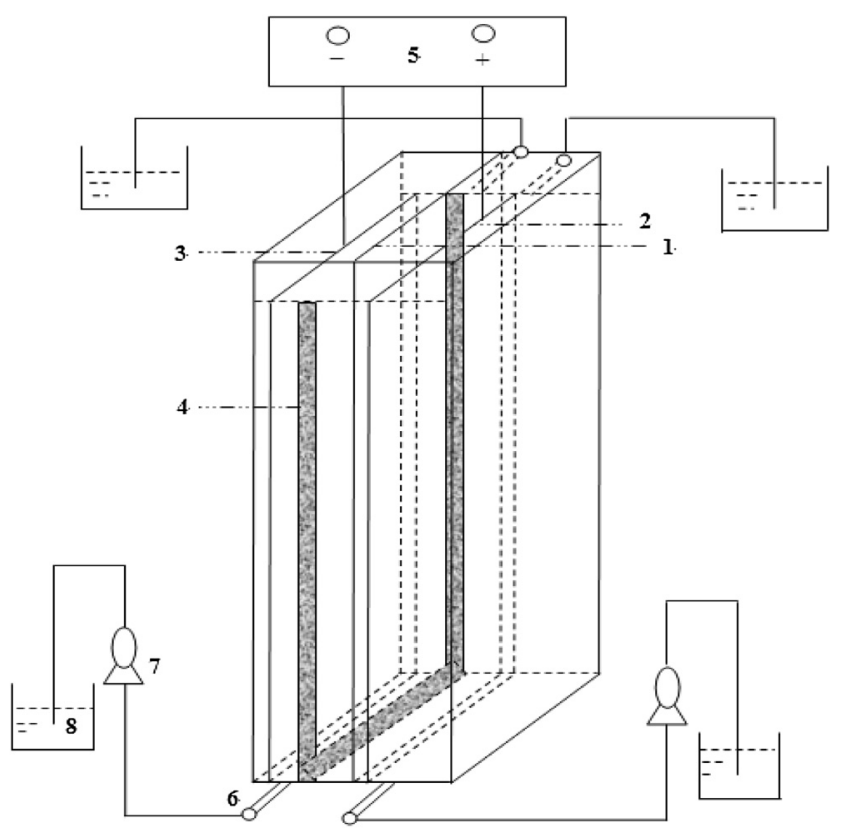

Fig. 1 - The schematic diagram of the three-dimensional electro-catalytic reactor 1 . Proton exchange membrane; 2. $\mathrm{RuO}_{2}-\mathrm{Ti}$ anode; 3. Pd-C cathode; 4. Pd-GAC catalysts; 5. Electrochemical workstation; 6. Inlet; 7. Peristaltic pump; 8. Reaction solution. 
exchange membrane (Nafion 117, Dupont). The electrodeposited Pd-C electrode was used as cathode with an apparent surface area of $100 \mathrm{~cm}^{2}$, and $\mathrm{RuO}_{2} / \mathrm{Ti}$ electrode with the same area was used as anode. The Pd-GAC particles were used as fixed filler of the cathode cell with a total effective volume of $100 \mathrm{~mL}$. The distance between the $\mathrm{Pd}-\mathrm{C}$ electrode and $\mathrm{RuO}_{2} / \mathrm{Ti}$ electrode was $4 \mathrm{~cm}$. The reactor was controlled by a DC power supply source AMERLLPS302A (Dahua instrument corporation of Beijing).

HAAs-spiked tap water was used to investigate the removal capability of the above reactor. The electrochemical experiment was performed in a continuous flow mode at a constant current density. The influent with a given concentration of HAAs was pumped into the reactor from a reservoir with a given rate. At an appropriate time intervals, samples of $10 \mathrm{~mL}$ were taken from the reactor outlet and analyzed to determine the concentration of HAAs. Effects of current density, hydraulic residence time (HRT), and the initial concentration of HAAs were investigated.

\subsection{Analysis method}

The concentration of HAA in the effluent from the cathode cell was measured using a Dionex-4500i ion chromatograph (IC) with an IonPac AS-19 anion-exchange analytical column and an IonPac AG19 guard column. Mobile phase eluent for the IC was $\mathrm{KOH}$ solution, and the flow rate was $1.0 \mathrm{~mL} / \mathrm{min}$. The concentration of chloroacetic acids was obtained under gradient elution conditions (0.0-18.0 min: 10.0 mM KOH; 18.1 to 30.0: $35.0 \mathrm{mM} \mathrm{KOH} ; 30.1$ to $35.0: 10.0 \mathrm{mM} \mathrm{KOH})$. The precision of the acetate mass balance in these measurements was ca. $95-105 \%$ of the nominal value. The concentrations of $\mathrm{Ca}^{2+}$ and $\mathrm{Mg}^{2+}$ in the influent and effluent were measured by the inductively coupled plasma optical emission spectrometer (ICP-OES, PerkinElmer Co.).

\subsection{Electrode characterization}

Morphological and elemental analysis of the Pd-C electrode and Pd-GAC particles were performed by scanning electron microscopy (SEM) and energy-dispersive X-ray spectroscopy (EDX) using a JSM 6301 microscope. The specific surface area was measured by nitrogen adsorption using the BET method with a Micromeritics ASAP 2000 (Micromeritics Co., USA) surface area analyzer. X-ray photoelectron spectroscopy (XPS) analysis was performed with a Kratos AXIS Ultra X-ray photoelectron spectrometer, and details of XPS were included in the Supporting Information. X-ray powder diffraction (XRD) measurements were performed to characterize the surface composition of the Pd-C electrode and Pd-GAC particles, by using an X'Pert PRO Powder diffractometer machine (PANalytical Co.) with $\mathrm{Ni}$-filtered $\mathrm{Cu} \mathrm{K}_{\alpha}$ radiation from $5^{\circ}$ to $90^{\circ}$ (in 20). Specific surface area and pore analysis of the catalyst were performed with the ASAP 2000 (Micromeritics, USA).

\section{Results and discussion}

\subsection{Electrochemical reduction performance}

Fig. 2 shows the reduction of HAAs in the three-dimensional electrochemical reactor for the continuous running. Under a current density of $0.3 \mathrm{~mA} / \mathrm{cm}^{2}$, HAAs in the effluent were reduced below $60 \mu \mathrm{g} / \mathrm{L}$ within hydraulic retention time (HRT) of $20 \mathrm{~min}$ for $30 \mathrm{~d}$. The initial concentration of HAAs was $120 \mu \mathrm{g} / \mathrm{L}$, including $20 \mu \mathrm{g} / \mathrm{L}$ for DBAA, $50 \mu \mathrm{g} / \mathrm{L}$ for DCAA and TCAA, respectively. $32.50 \mathrm{mg} / \mathrm{L} \mathrm{Ca}^{2+}$ and $15.83 \mathrm{mg} / \mathrm{L} \mathrm{Mg}^{2+}$ were included in the influent. These results indicated that the three-dimensional reactor presented high activity in electrocatalytic removal of HAAs.

Adsorption of HAAs by the Pd-C electrode and Pd-GAC are presented in the Supporting Information (Fig. S1). With the same initial concentration of MCAA, DCAA, TCAA, MBAA and TBAA $(120 \mu \mathrm{g} / \mathrm{L})$, the Pd-C cathode and Pd-GAC exhibited low adsorption capability of HAAs $(<3 \%)$. Thus, it was concluded that the electrocatalytic reduction was the primary process for HAAs removal in this study. A comparison of HAAs removal efficiencies under various processes was also performed. As shown in Fig. 3, the removal efficiency by Pd-C cathode or PdGAC process was lower than that by the combined process of Pd-C cathode and Pd-GAC together. Meantime, the effluent from Pd-C cathode was furthermore treated by Pd-GAC process. It is clear that the removal efficiency of HAAs in this process is still lower than that by the combined process of $\mathrm{Pd}$ $C$ cathode and Pd-GAC together. The above results indicated the high performance of a three-dimensional electrochemical reactor with Pd-GAC particles as a fixed filler and Pd-modified carbon paper as cathode for the HAAs removal.

In the treatment process, white precipitate on the Pd-GAC particles was observed. Compared with that in the influent, the concentration of $\mathrm{Ca}^{2+}$ and $\mathrm{Mg}^{2+}$ was decreased by $50-60 \%$ and by $80 \%$ in the effluent, respectively. Thus, it was suggested that the white precipitates should be calcium hydroxide $\left(\mathrm{Ca}(\mathrm{OH})_{2}\right)$ and magnesium hydroxide $\left(\mathrm{Mg}(\mathrm{OH})_{2}\right)$. The concentration of $\mathrm{HAA}_{5}$ was higher than $60 \mu \mathrm{g} / \mathrm{L}$ at $8 \mathrm{~d}$. The adsorption of the precipitate to the Pd-C cathode and Pd-GAC will decrease the activity of the reaction system. Besides, chloride ion $\left(\mathrm{Cl}^{-}\right)$liberated during the dechlorination process, which covered available active sites of catalysts, leading to the decrease in the removal efficiency of HAAs (Li et al., 2012; Wang et al., 2010). Therefore, the electrochemical reaction

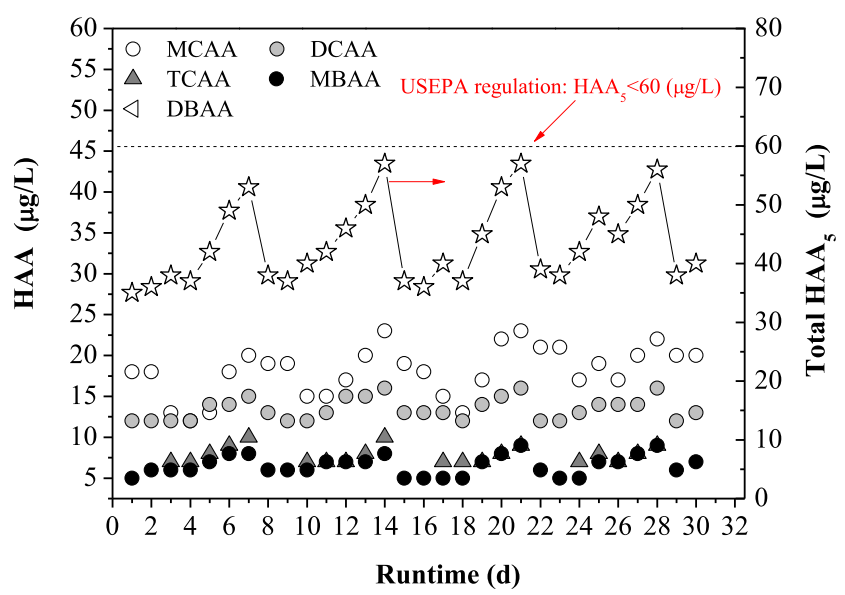

Fig. 2 - HAAs concentration in the effluent of continuous running (initial HAAs concentration: $120 \mu \mathrm{g} / \mathrm{L}$; current density: $0.3 \mathrm{~mA} / \mathrm{cm}^{2}$; HRT: $20 \mathrm{~min} ; \mathrm{Ca}^{2+}$ concentration: $32.50 \mathrm{mg} / \mathrm{L} ; \mathrm{Mg}^{2+}$ concentration: $15.83 \mathrm{mg} / \mathrm{L}$ ). 


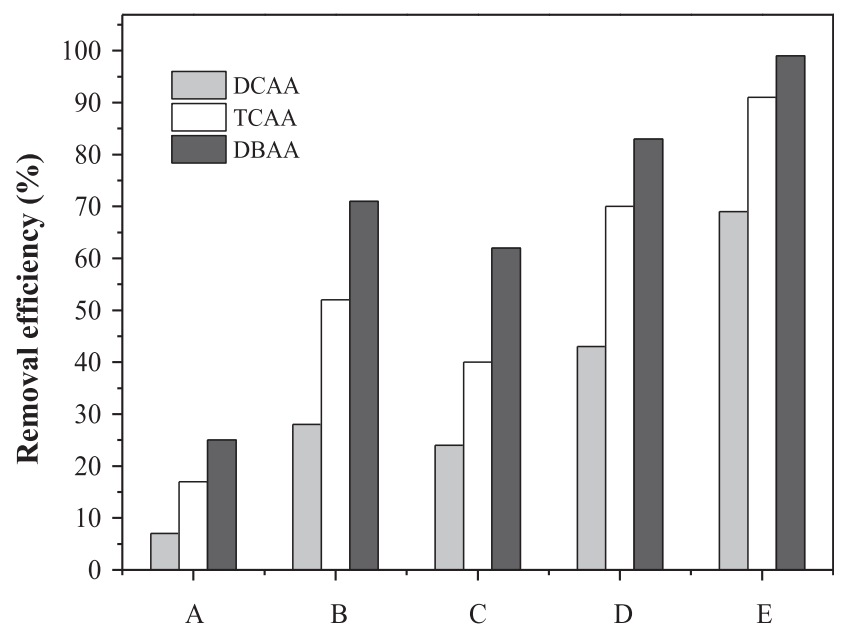

Fig. 3 - A comparison of haloacetic acids removal efficiency under various processes (initial HAA concentration: $120 \mu \mathrm{g} /$ L; initial pH: 7; $\mathrm{Na}_{2} \mathrm{SO}_{4}$ concentration: $200 \mathrm{mg} / \mathrm{L}$; current density: $0.3 \mathrm{~mA} / \mathrm{cm}^{2}$; HRT: $20 \mathrm{~min}$ ) (A, C paper cathode + GAC; B, Pd-C cathode + GAC; C, C paper cathode + Pd-GAC; D, effluent from Pd-C cathode treated by C paper cathode + Pd-GAC; E, Pd-C cathode + Pd-GAC).

system was stopped at $8,15,22$, and 29 d for back washing; meanwhile, the Pd-C cathode and Pd-GAC were regenerated with dilute $\mathrm{HCl}(1.4 \mathrm{~mol} / \mathrm{L})$ to remove these precipitates. After that, the three-dimensional electrochemical reactor exhibited a high electrocatalytic activity in the reduction of HAAs again.

\subsection{Effect of current density on the removal efficiency of haloacetic acids}

The electrocatalytic reduction of HAAs was performed with various current densities ranging from 0.1 to $0.9 \mathrm{~mA} / \mathrm{cm}^{2}$. It is shown in Fig. 4 that the removal of HAAs was enhanced with increasing current density, with a maximum removal

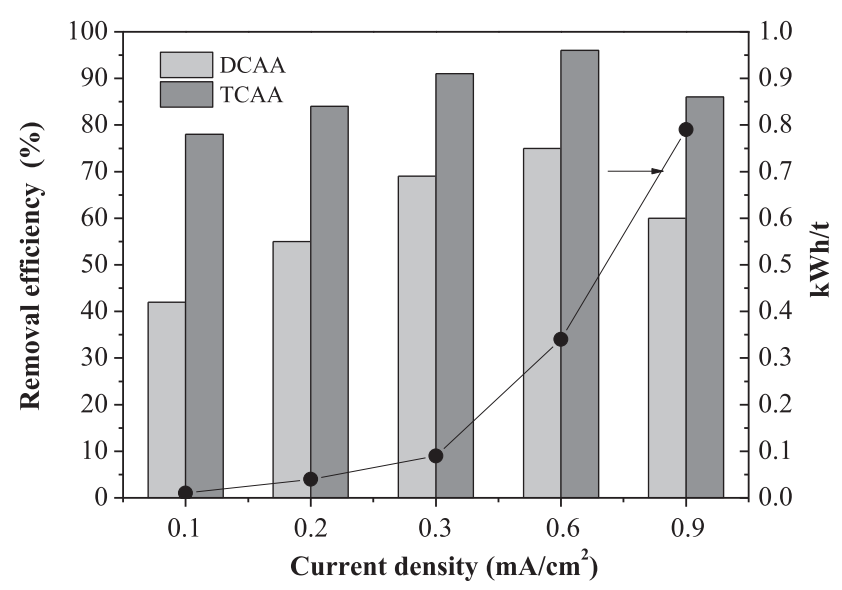

Fig. 4 - Effect of current density on the removal of HAAs and the energy consumption (initial HAAs concentration: $120 \mu \mathrm{g} / \mathrm{L}$; initial pH: 7; $\mathrm{Na}_{2} \mathrm{SO}_{4}$ concentration: $200 \mathrm{mg} / \mathrm{L}$; HRT: $20 \mathrm{~min}$ ). efficiency observed at $0.6 \mathrm{~mA} / \mathrm{cm}^{2}$. A slight decrease is occurred when the current density is increased to $0.9 \mathrm{~mA} / \mathrm{cm}^{2}$. Corresponding to the current densities of $0.1,0.2,0.3,0.6$, and $0.9 \mathrm{~mA} / \mathrm{cm}^{2}$, the electrode potentials were determined to be $3.37,3.63,4.03,4.76,5.45 \mathrm{~V}$ at the initial reaction period, respectively. With the reaction evolution, the electrode potentials increased slightly.

With the increase of the current density, more electrons took part in the dehalogenation process (Korshin and Jensen, 2001; Li et al., 2007; Altamar et al., 2010). In our previous work, it was exhibited that a decrease of the electrode potential resulted in the increase of the reaction rate constants of chloroacetic acids (Li et al., 2012). Li et al. also reported that HAAs reduction happened at potentials more cathodic than $-1.0 \mathrm{~V}$ where molecular hydrogen would evolve (Li et al., 2007). However, when the current density was higher than $0.6 \mathrm{~mA} / \mathrm{cm}^{2}$, the large amount of hydrogen bubbles would interference the electron transfer or HHAs diffusion at the electrode surface, which will lead to the decrease of the reduction efficiency of HAAs. Thus, this would inevitably deactivate the Pd-C electrode and Pd-GAC. At the current density of 0.3 and $0.6 \mathrm{~mA} / \mathrm{cm}^{2}$, similar removal efficiency of HAAs is exhibited. With respect to the energy cost, the calculated energy consumption of $0.34 \mathrm{kWh} / \mathrm{t}$ at $0.6 \mathrm{~mA} / \mathrm{cm}^{2}$ was much higher than $0.09 \mathrm{kWh} / \mathrm{t}$ at $0.3 \mathrm{~mA} / \mathrm{cm}^{2}$. Therefore, the current density of $0.3 \mathrm{~mA} / \mathrm{cm}^{2}$ was selected in the subsequent experiments.

\subsection{Effect of hydraulic retention time on the removal} efficiency of haloacetic acids

Effect of HRT on the reduction removal of HAAs is shown in Fig. 5. The removal efficiency at HRT $5 \mathrm{~min}$ and $10 \mathrm{~min}$ was quite low. By contrast, the removal efficiency of HAAs is obviously enhanced when HRT was increased to $20 \mathrm{~min}$. The removal efficiency of DCAA and TCAA are determined to be $69 \%$ and $91 \%$, respectively. With the increase of HRT to 30 and

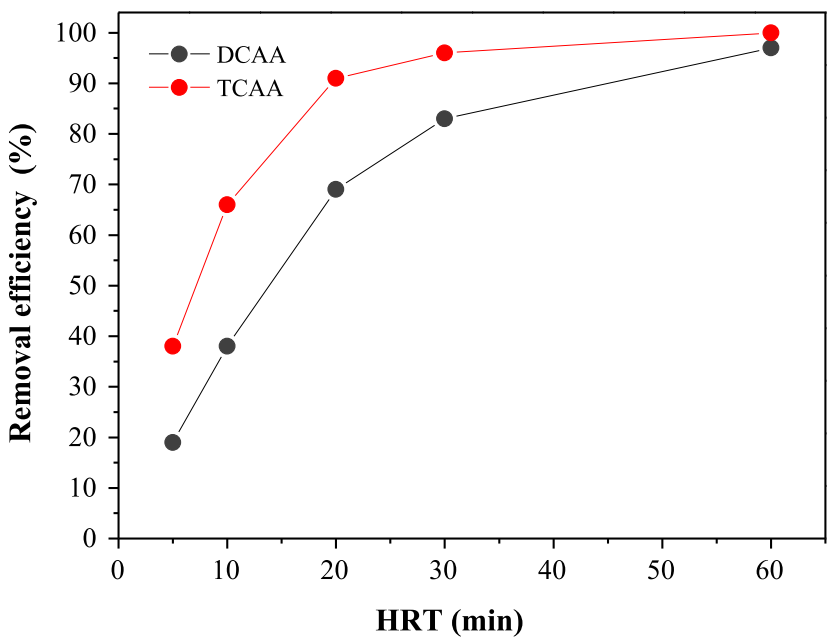

Fig. 5 - Effect of HRT on the reduction removal of HAAs (initial HAAs concentration: $120 \mu \mathrm{g} / \mathrm{L}$; initial pH: 7; $\mathrm{Na}_{2} \mathrm{SO}_{4}$ concentration: $200 \mathrm{mg} / \mathrm{L}$; current density: $0.3 \mathrm{~mA} / \mathrm{cm}^{2}$ ). 
$60 \mathrm{~min}$, a slight increase of the removal efficiency of HAAs is observed. Therefore, the value of HRT was chosen as $20 \mathrm{~min}$.

\subsection{Effect of initial HAAs concentration on the removal efficiency of haloacetic acids}

Initial concentration of HAAs was an important factor for the removal efficiency during electrocatalytic process (Li et al., 2007, 2012). As shown in Fig. 6, the reduction removal efficiency of HAAs increases slightly with increasing the initial HAAs concentration. This is because that the electrons are enough to be used in the reduction process with the increase of the initial HAAs concentration, then the interfacial reaction was enhanced leading to an increase in removal efficiency of HAAs (Li et al., 2012). Combined with the effect of current density and initial HAAs concentration on the removal efficiency of HAAs, it could be deduced that electron transfer and HAAs diffusion were simultaneously responsible for controlling the electrochemical reduction process when the current density was below $0.6 \mathrm{~mA} / \mathrm{cm}^{2}$ with the initial HAAs concentration of $120-600 \mu \mathrm{g} / \mathrm{L}$. Both increase of the current density and initial HAAs concentration could improve the removal efficiency of HAAs. By contrast, when the current density was higher than $0.6 \mathrm{~mA} / \mathrm{cm}^{2}$, the HAAs diffusion may play a primary role for the rate-limiting step of the electrochemical reduction of HHAs.

\section{5. $p H$ and turbidity variations of the influent and effluent}

Fig. 7 shows the $\mathrm{pH}$ and turbidity variations of the influent and effluent during the electro-dechlorination process. As shown in Fig. $7(\mathrm{a})$, the $\mathrm{pH}$ value of effluent was slightly higher than that of the influent. This is attributed to the consumption of atomic $\mathrm{H}^{*}$, which was formed during the process that $\operatorname{Pd}(0)$ used the electron delivered from the cathode to transform $\mathrm{H}^{+}$ into atomic $\mathrm{H}^{*}$. Moreover, indirect reduction by atomic $\mathrm{H}^{*}$ was

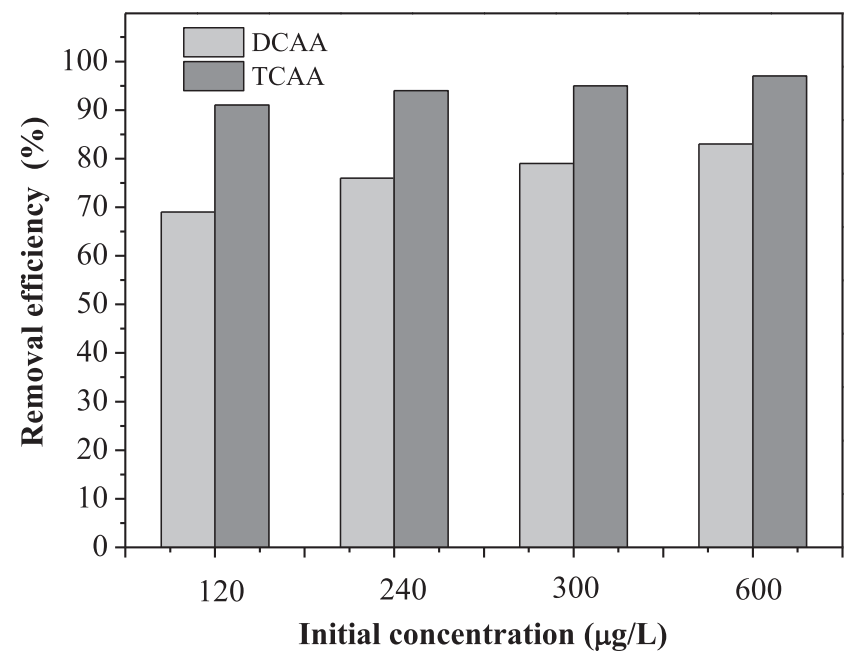

Fig. 6 - Effect of initial HAAs concentration on the reduction removal of HAAs (initial $\mathrm{pH}$ : 7; $\mathrm{Na}_{2} \mathrm{SO}_{4}$ concentration: $200 \mathrm{mg} / \mathrm{L}$; current density: $0.3 \mathrm{~mA} / \mathrm{cm}^{2}$; HRT: $20 \mathrm{~min})$.
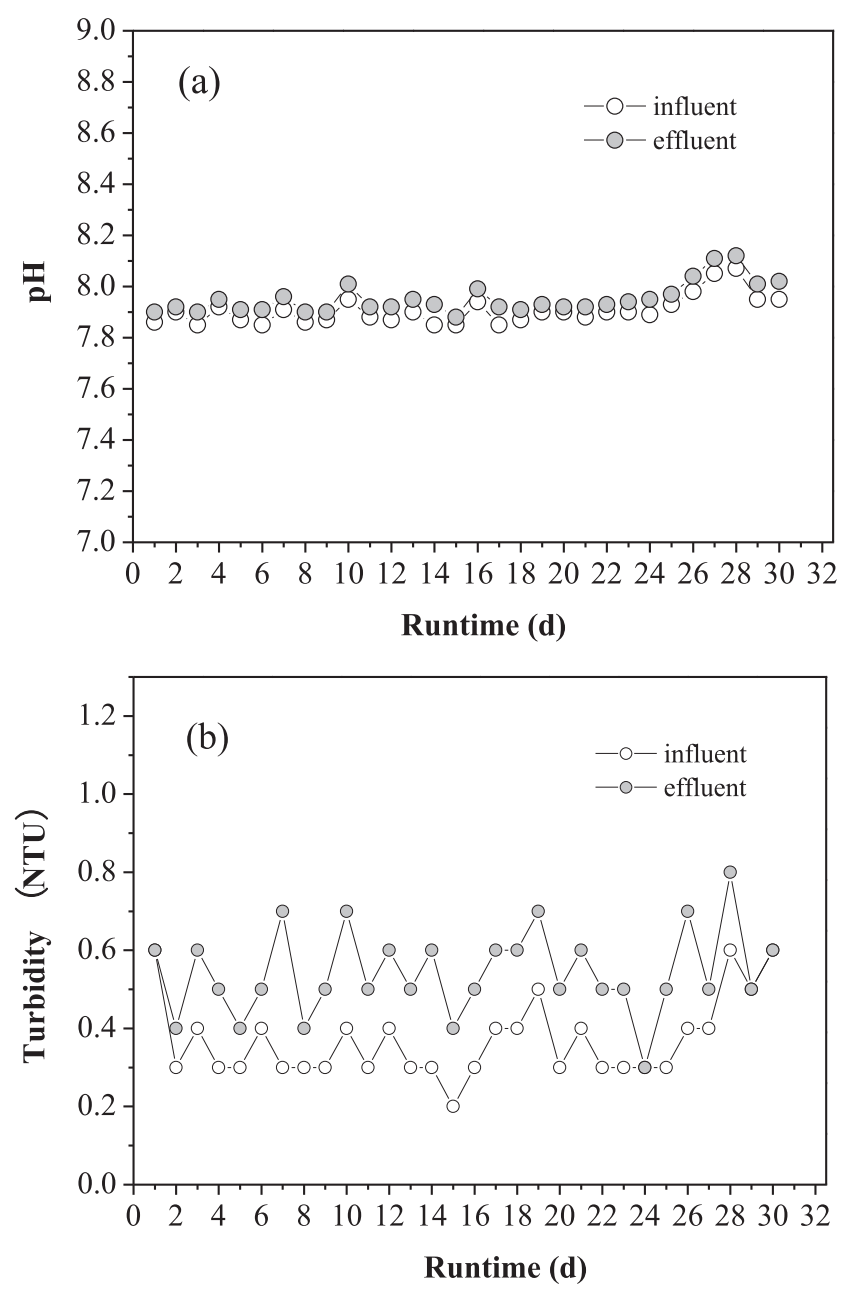

Fig. $7-\mathrm{pH}$ and turbidity variations of the influent and effluent (initial HAAs concentration: $120 \mu \mathrm{g} / \mathrm{L}$; current density: $0.3 \mathrm{~mA} / \mathrm{cm}^{2}$; HRT: $20 \mathrm{~min}$; $\mathrm{Ca}^{2+}$ concentration: $32.50 \mathrm{mg} / \mathrm{L} ; \mathrm{Mg}^{2+}$ : $\left.15.83 \mathrm{mg} / \mathrm{L}\right)$.

the primary process to realize the complete dechlorination of chloroacetic acids (Li et al., 2012; Wang et al., 2010). Additionally, it was shown in Fig. 7(b) that the turbidity of the effluent was also slightly higher than that of the influent, while the $\mathrm{pH}$ and turbidity of the effluent was in the range of the drinking water standard regulated by USEPA. The increased turbidity in the effluent after electrolysis may be induced by the precipitates of calcium and magnesium hydroxides.

\subsection{Electrode characterization}

\subsubsection{SEM-EDX analysis}

SEM images and EDX analysis of the Pd-C cathode and Pd-GAC before and after the electrochemical reaction are presented in Figs. 8 and 9, respectively. It can be shown that the electrodeposited $\operatorname{Pd}(0)$ particles as a film were tightly attached on the surface of the carbon paper (Fig. 8(a)). Furthermore, the tiny gaps among the $\mathrm{Pd}(0)$ particles can provide an optimal channel for the reduction of HAAs molecules (Fig. 8(b)). After $7 \mathrm{~d}$, 

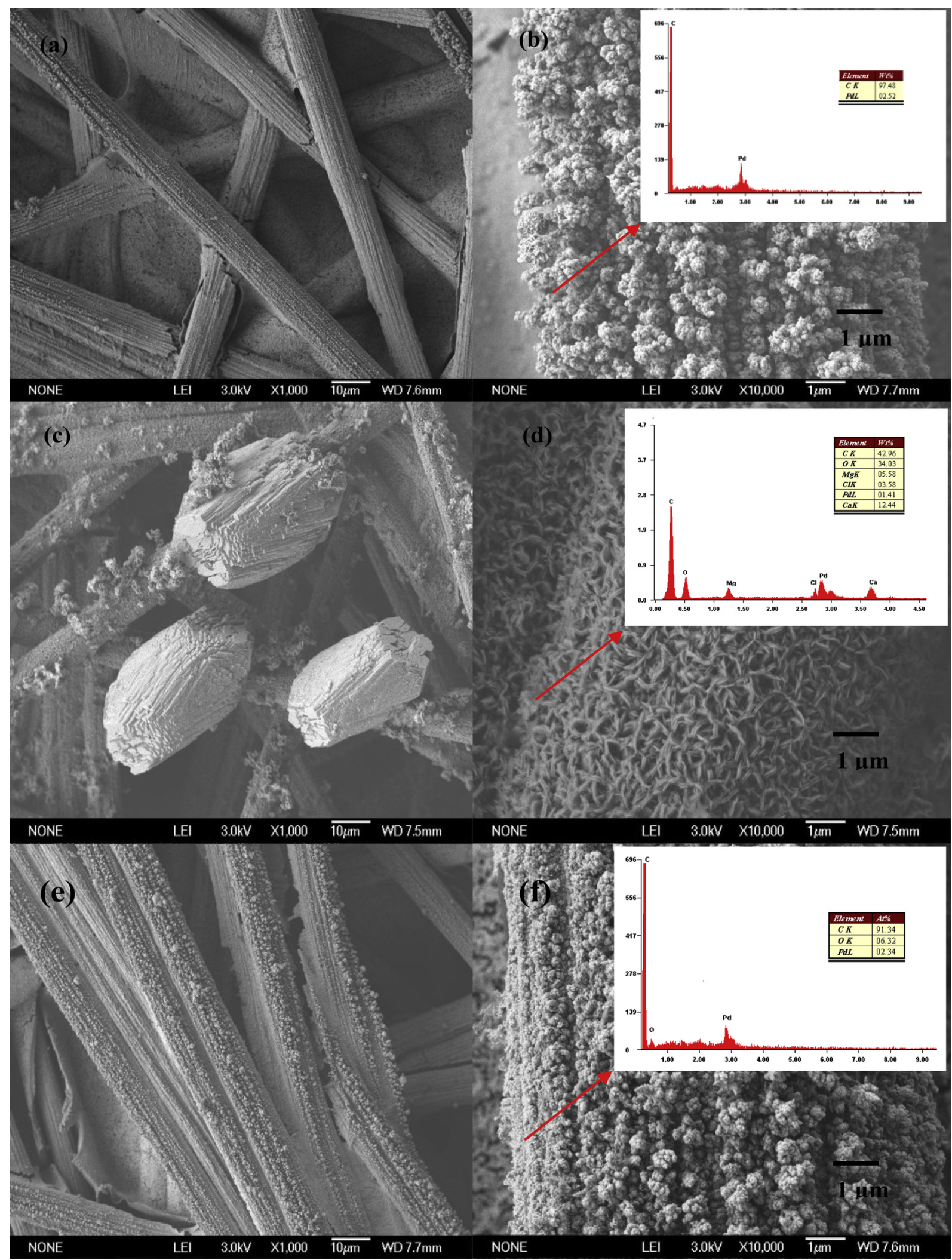

Fig. 8 - SEM images and EDX analysis of the Pd-C cathode (a) the Pd-C cathode before the reaction with magnification to 1000; (b) the Pd-C cathode before the reaction with magnification to 10,000; (c) the Pd-C cathode after the reaction with magnification to 1000; (d) the Pd-C cathode after dehalogenation with magnification to 10000; (e) regeneration of the Pd-C cathode with magnification to 1000; (f) regeneration of the Pd-C cathode with magnification to 10000. 


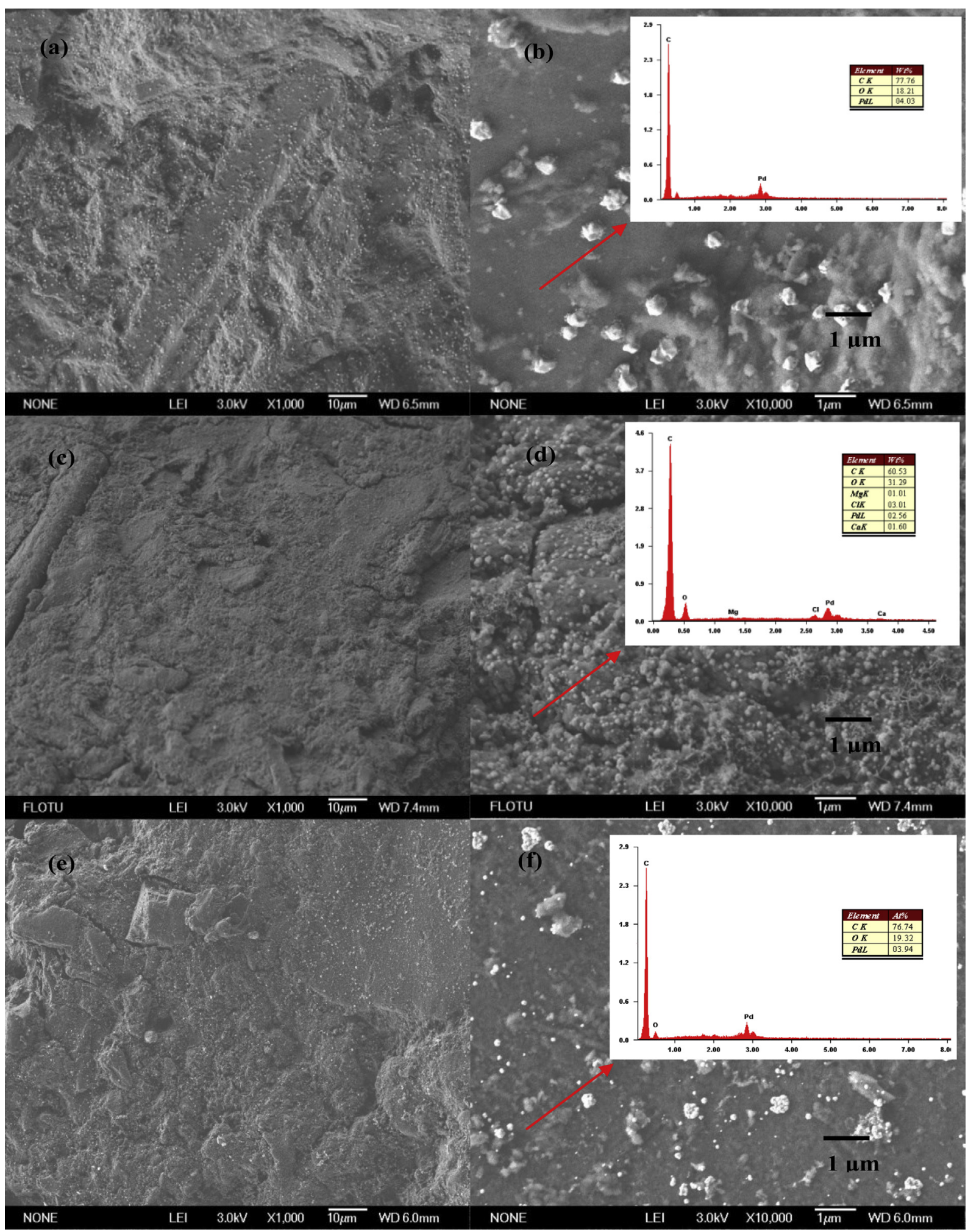

Fig. 9 - SEM images and EDX analysis of the Pd-GAC particles (a) the Pd-GAC particles before dehalogenation with magnification to 1000; (b) the Pd-GAC particles before dehalogenation with magnification to 10000; (c) the Pd-GAC particles after dehalogenation with magnification to 1000; (d) the Pd-GAC after dehalogenation with magnification to 10000; (e) regeneration of the Pd-GAC with magnification to 1000; (f) regeneration of the Pd-GAC with magnification to 10000.

the SEM-EDX results indicate that the $\mathrm{Ca}(\mathrm{OH})_{2}$ and $\mathrm{Mg}(\mathrm{OH})_{2}$ particles were precipitated on the carbon fiber (Fig. 8(c) and (d)). Besides, EDX analysis of the electrode exhibits the characteristic peaks of $\mathrm{Cl}$, indicating that $\mathrm{Cl}^{-}$was generated during the reductive dechlorination. The precipitates of the $\mathrm{Ca}(\mathrm{OH})_{2}$ and $\mathrm{Mg}(\mathrm{OH})_{2}$ particles can take up the active sites of the Pd catalysts. Therefore, the Pd-C cathode need to be regenerated with dilute $\mathrm{HCl}$ solution. As shown in Fig. 8(e) and (f), the 
precipitates on the electrode were nearly completely removed, and the uniform dispersion and small size of the electrodeposited Pd nanoparticles on the carbon paper were the same as that on the freshly prepared $\mathrm{Pd}-\mathrm{C}$ cathode.

As shown in Fig. 9(a) and (b), the calcined Pd particles exhibited knobs deposited on the GAC surface, thus the calcined Pd particles on GAC were not uniform as the electrodeposited Pd particles on the carbon paper. Additionally, the SEM image indicates that the particle size of the calcined Pd was larger than that of the electrodeposited Pd particles. For $7 \mathrm{~d}$, the precipitates of $\mathrm{Ca}(\mathrm{OH})_{2}$ and $\mathrm{Mg}(\mathrm{OH})_{2}$ were also attached onto the GAC particles (Fig. 9(c) and (d)). Pd-GAC was also regenerated with dilute $\mathrm{HCl}$, most of the precipitate was removed after the regeneration treatment as confirmed by the SEM-EDX analysis (Fig. 9(e) and (f)).

\section{6. 2 BET analysis}

BET analysis of the Pd-GAC particles was performed. As shown in Table 1, the specific surface area and pore volume of the GAC decreased after loading Pd particles, resulting from the blockage of some pores in GAC. For the Pd-GAC samples, the specific surface area, pore diameter and pore volume decreased remarkably after $7 \mathrm{~d}$ treatment. This is because that GAC pores were blocked by metal hydroxides produced during the electrocatalytic reduction process, thereby decreasing the contact area between the Pd-GAC and HAAs. As a result, the electrocatalytic activity of the Pd-GAC decreased apparently. It is noteworthy that the specific surface area pore volume and pore diameter of the Pd-GAC increased significantly after the regeneration treatment. Combined with the SEM-EDX analysis, it can be deduced that precipitates on the Pd-GAC were efficiently removed and its activity towards reduction removal of HAAs was regenerated.

\subsubsection{XRD and XPS analysis}

The XRD patterns of the Pd-C electrode and Pd-GAC particles before and after the electrochemical reduction of HHAs are presented in the Supporting Information (Fig. S2). The diffractogram of the Pd-C electrode and the Pd-GAC particles before and after the electrochemical reaction both shows the metallic Pd peaks (Palomares et al., 2011). In addition, the XRD patterns of the Pd-C electrode before and after the reaction, as well as the Pd-GAC particles were almost the same, which can account for the stable electrocatalysis activity of the electrochemical system.

Furthermore, the XPS patterns of the Pd-C electrode before and after the electrochemical reactions are presented in Fig. 10(a). It was reported that the binding energy for metallic Pd varies between 335.0 and $335.5 \mathrm{eV}$, whereas the energy for

Table 1 - BET analysis of the GAC and Pd-GAC particles.

\begin{tabular}{lccc} 
& $\begin{array}{c}\text { Specific } \\
\text { surface } \\
\text { area }\left(\mathrm{m}^{2} / \mathrm{g}\right)\end{array}$ & $\begin{array}{c}\text { Pore } \\
\text { volume } \\
\left(\mathrm{cm}^{3} / \mathrm{g}\right)\end{array}$ & $\begin{array}{c}\text { Pore } \\
\text { diameter } \\
(\mathrm{nm})\end{array}$ \\
\hline GAC & 1591 & 1.0709 & 2.674 \\
Pd-GAC & 1043 & 0.7287 & 2.783 \\
Pd-GAC after reaction & 923 & 0.5600 & 2.088 \\
Pd-GAC after & 1040 & 0.7290 & 2.769 \\
$\quad$ regeneration & & & \\
\hline
\end{tabular}

$\mathrm{Pd}^{2+}$ is $337.5 \mathrm{eV}$ (Muftikian et al., 1996). For the Pd-C electrode, the binding energies of $\mathrm{Pd} 3 \mathrm{~d}$ peaks appear at $335.3 \mathrm{eV}$ and $340.6 \mathrm{eV}$, indicating the $\operatorname{Pd}(0)$ species before the electrochemical reaction. After $1 \mathrm{~d}$, the binding energy transition increases slightly, indicating the presence of $\mathrm{Pd}^{0}$ and $\mathrm{Pd}^{2+}$ species for the used Pd-C cathode. Moreover, after $30 \mathrm{~d}$, the valence state allocations of $\mathrm{Pd}^{0}$ and $\mathrm{Pd}^{2+}$ remain nearly constant, indicating the stability of the Pd-C electrode. The similar valence state of Pd was detected in the Pd-GAC particles (Fig. 10(b)). In the electrocatalytic reduction of HAAs, the transitional $\mathrm{C}-\mathrm{Pd}-\mathrm{Cl}$ bond was formed, which could promote the indirect electroreduction process of HAAs (Li et al., 2012). The concentration of $\mathrm{Pd}^{2+}$ in the effluent was below the detection limit as measured by the ICP-OES, indicating the stability of the Pd-C electrode and Pd-GAC particles.

\section{Conclusions}

In summary, the three-dimensional electrochemical reactor with the Pd-GAC particles as a fixed filler of the cathode cell showed high and stable activity in the electroreduction of HAAs. Considering the energy consumption and capacity for the reactor, the optimal value of the current density and HRT
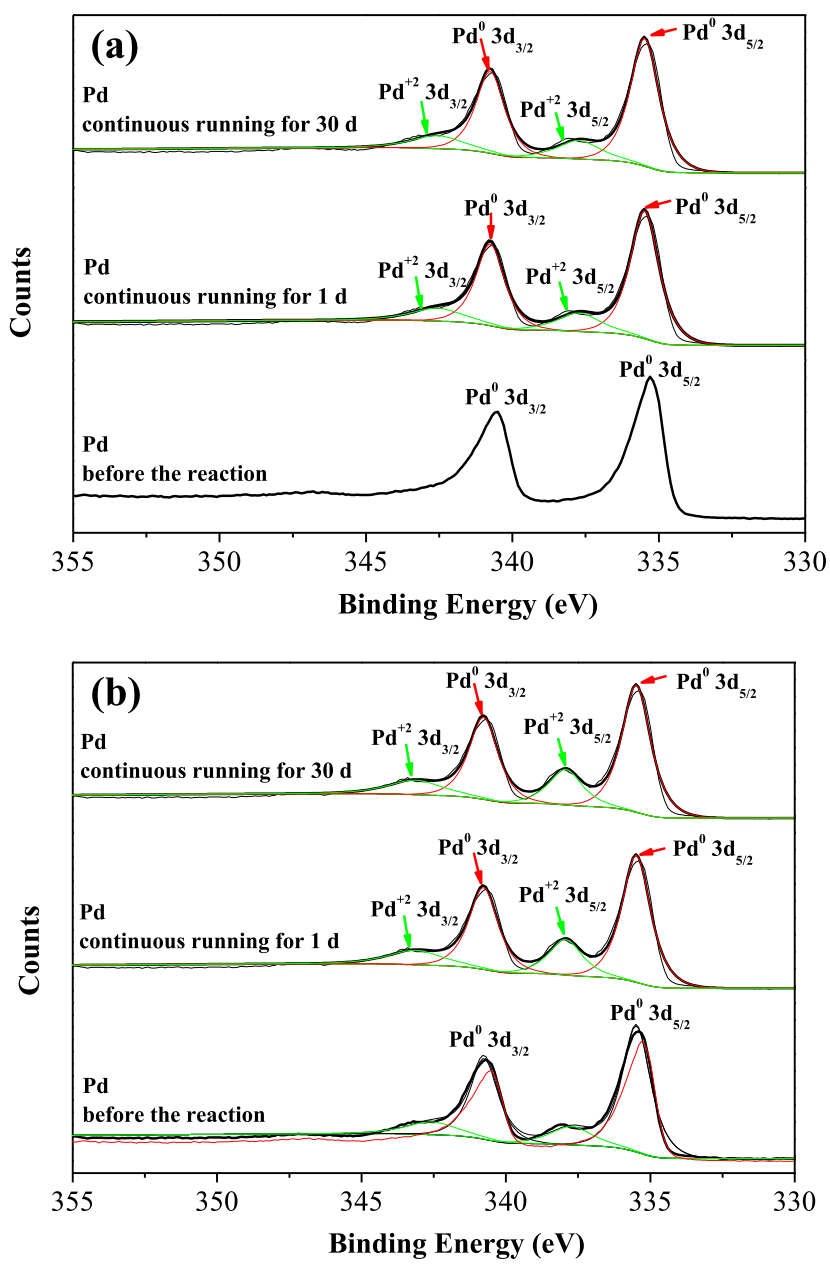

Fig. 10 - XPS analysis of the Pd-C cathode and the Pd-GAC particles before and after the electrochemical reduction reaction (a) the Pd-C cathode; (b) the Pd-GAC particles. 
was determined. It could be deduced that electron transfer and concentration diffusion governed the electro-reduction process simultaneously when current density was less than $0.6 \mathrm{~mA} / \mathrm{cm}^{2}$ with initial HAAs concentration in the range of 120-600 $\mu \mathrm{g} / \mathrm{L}$. While current density was higher than $0.6 \mathrm{~mA} /$ $\mathrm{cm}^{2}$, the HAAs diffusion became the rate-limiting step. The $\mathrm{pH}$ and turbidity of the effluent was in the range of the drinking water standard regulated by USEPA. After being regenerated, the Pd-C electrode and Pd-GAC particles exhibit high electrochemical reduction activity. The XPS result revealed that the transitional $\mathrm{C}-\mathrm{Pd}-\mathrm{Cl}$ bond was formed, which could promote the indirect process. Combined with the XRD analysis, the high stability of the Pd-C electrode and Pd-GAC particles was exhibited.

\section{Acknowledgments}

This work was supported by National Natural Science Foundation of China (No. 51290282; 51222802) and the National Basic Research Program of China (Grant 2010CB933604).

\section{Appendix A. Supplementary data}

Supplementary data related to this article can be found at http://dx.doi.org/10.1016/j.watres.2013.12.028.

\section{R E F E R E N C E S}

Altamar, L., Fernandez, L., Borras, C., Mostany, J., Carrero, H., Scharifker, B., 2010. Electroreduction of chloroacetic acids (mono-, di- and tri-) at polyNi (II)-tetrasulfonated phthalocyanine gold modified electrode, Sensor. Actuat. B: Chem. 146, 103-110.

Christman, R.F., Norwood, D.L., Millington, D.S., Johnson, J.D., Stevens, A.A., 1983. Identity and yields of major halogenated products of aquatic fulvic acid chlorination. Environ. Sci. Technol. 17, 625-628.

Czili, H., Horvath, A., 2009. Photodegradation of chloroacetic acids over bare and silver-deposited $\mathrm{TiO}_{2}$ : identification of species attacking model compounds, a mechanistic approach. Appl. Catal. B: Environ. 89, 342-348.

De Pedro, Z.M., Díaz, E., Mohedano, A.F., Casas, J.A., Rodriguez, J.J., 2011. Compared activity and stability of $\mathrm{Pd} / \mathrm{Al}_{2} \mathrm{O}_{3}$ and $\mathrm{Pd} / \mathrm{AC}$ catalysts in 4-chlorophenol hydrodechlorination in different $\mathrm{pH}$ media. Appl. Catal. B: Environ. 103, 128-135.

Gan, W.H., Guo, W.H., Mo, J.M., He, Y.S., Liu, Y.J., Liu, W., Liang, Y.M., Yang, X., 2013. The occurrence of disinfection by-products in municipal drinking water in China's Pearl River Delta and a multipathway cancer risk assessment. Sci. Total. Environ. 447, 108-115.

Hong, Y., Song, H., Karanfil, T., 2013. Formation of haloacetic acids from dissolved organic matter fractions during chloramination. Water Res. 47, 1147-1155.

Hozalski, R.M., Zhang, L., Arnold, W.A., 2001. Reduction of haloacetic acids by $\mathrm{Fe}^{\mathrm{O}}$ : implications for treatment and fate. Environ. Sci. Technol. 35, 2258-2263.
Korshin, G.V., Jensen, M.D., 2001. Electrochemical reduction of haloacetic acids and exploration of their removal by electrochemical treatment. Electrochim. Acta 47, 747-751.

Kong, W.P., Wang, B., Ma, H.Z., Gu, L., 2006. Electrochemical treatment of anionic surfactants in synthetic wastewater with three-dimensional electrodes. J. Hazard. Mater. 137, 1532-1537.

Linge, K.L., Blythe, J.W., Busetti, F., Blair, P., Rodriguez, C., Heitz, A., 2013. Formation of halogenated disinfection byproducts during microfiltration and reverse osmosis treatment: implications for water recycling. Sep. Purif. Technol. 104, 221-228.

Li, A.Z., Zhao, X., Hou, Y.N., Liu, H.J., Wu, L.Y., Qu, J.H., 2012. The electrocatalytic dechlorination of chloroacetic acids at electrodeposited Pd/Fe-modified carbon paper electrode. Appl. Catal. B: Environ. 111-112, 628-635.

Li, T., Farrell, J., 2000. Reductive dechlorination of trichloroethene and carbon tetrachloride using iron and palladized-iron cathodes. Environ. Sci. Technol. 34, 173-179.

Li, Y.P., Cao, H.B., Zhang, Y., 2007. Reductive dehalogenation of haloacetic acids by hemoglobin-loaded carbon nanotube electrode. Water Res. 41, 197-205.

Lingaiah, N., Uddin, M.A., Muto, A., Sakata, Y., 1999. Hydrodechlorination of chlorinated hydrocarbons over metalcarbon composite catalysts prepared by a modified carbothermal reduction method. Chem. Commun., 1657-1658.

Mackenzie, K., Frenzel, H., Kopinke, F.D., 2006. Hydrodehalogenation of halogenated hydrocarbons in water with Pd catalysts: reaction rates and surface competition. Appl. Catal. B: Environ. 63, 161-167.

Mascia, M., Vacca, A., Palmas, S., 2012. Fixed bed reactors with three dimensional electrodes for electrochemical treatment of waters for disinfection. Chem. Eng. J. 211-212, 479-487.

Martinez, M.M., Sainero, L.M.G., Montero, M.A.A., Bedia, J., Rodriguez, J.J., 2013. Comparison of different precious metals in activated carbon-supported catalysts for the gas-phase hydrodechlorination of chloromethanes. Appl. Catal. B: Environ. 132-133, 256-265.

McRae, B.M., LaPara, T.M., Hozalski, R.M., 2004. Biodegradation of haloacetic acids by bacterial enrichment cultures. Chemosphere 55, 915-925.

Muftikian, R., Nebesny, K., Fernando, Q., Korte, A.N., 1996. X-ray photoelectron spectra of the palladium-iron bimetallic surface used for the rapid dechlorination of chlorinated organic environmental contaminants. Environ. Sci. Technol. 30, 3593-3596.

Palomares, A.E., Franch, C., Corma, A., 2011. A study of different supports for the catalytic reduction of nitrates from natural water with a continuous reactor. Catal. Today 172, 90-94.

Pontinus, F.W., 1999. J.-Am. Water Works Assoc. 91, 46-58.

Rego, R., Oliveira, C., Velazquez, A., Cabot, P.L., 2010. A new route to prepare carbon paper-supported Pd catalyst for oxygen reduction reaction. Electrochem. Commun. 12, 745-748.

Spangeberg, D., Moller, U., Kleinermanns, K., 1996. Photooxidation of exhaust pollutants IV Photocatalytic and thermal decomposition of trichloroacetic acid: degradation efficiencies and products. Chemosphere 33, 43-49.

Tang, S., Wang, X.M., Yang, H.W., Xie, Y.F., 2013. Haloacetic acid removal by sequential zero-valent iron reduction and biologically active carbon degradation. Chemosphere 90, 1563-1567.

Wang, Y., Qu, J.H., 2006. Electrocatalytic reduction of nitrate in water with a palladium-modified copper electrode. Water Environ. Res. 78, 724-729. 
Wang, X.Y., Ning, P., Liu, H.L., Ma, J., 2010. Dechlorination of chloroacetic acids by Pd/Fe nanoparticles: effect of drying method on metallic activity and the parameter optimization. Appl. Catal. B: Environ. 94, 55-63.

Wei, L.Y., Guo, S.H., Yan, G.X., Chen, C.M., Jiang, X.Y., 2010. Electrochemical pretreatment of heavy oil refinery

wastewater using a three-dimensional electrode reactor. Electrochim. Acta 55, 8615-8620.
Xu, X., Weisel, C.P., 2003. Inhalation exposure to haloacetic acids and haloketones during showing. Environ. Sci. Technol. 37, 569-576.

Zhou, J., Han, Y.X., Wang, W.J., Xu, Z.Y., Wan, H.Q., Yin, D.Q., Zheng, S.R., Zhu, D.Q., 2013. Reductive removal of chloroacetic acids by catalytic hydrodechlorination over $\mathrm{Pd} / \mathrm{ZrO}_{2}$ catalysts. Appl. Catal. B: Environ. 134-135, 222-230. 